Slavica

bruxellensia

\section{Slavica bruxellensia}

Revue polyphonique de littérature, culture et histoire

slaves

$1 \mid 2008$

Théâtre

\title{
Małgorzata Małolepsza et Aneta Szymkiewicz, Hurra!!! Po Polsku 1
}

\section{Dagmara Gut}

\section{OpenEdition \\ Journals}

Édition électronique

URL : http://journals.openedition.org/slavica/247

DOI : $10.4000 /$ slavica. 247

ISSN : 2034-6395

\section{Éditeur}

Université libre de Bruxelles - ULB

\section{Édition imprimée}

Pagination : 71-72

ISSN : 2031-7654

Référence électronique

Dagmara Gut, « Małgorzata Małolepsza et Aneta Szymkiewicz, Hurra!!! Po Polsku 7 », Slavica bruxellensia [En ligne], 1 | 2008, mis en ligne le 15 octobre 2008, consulté le 22 septembre 2020. URL : http://journals.openedition.org/slavica/247 ; DOI : https://doi.org/10.4000/slavica.247

Ce document a été généré automatiquement le 22 septembre 2020

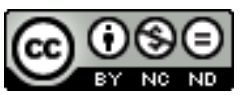

Les contenus de Slavica bruxellensia sont mis à disposition selon les termes de la Licence Creative Commons Attribution - Pas d'Utilisation Commerciale - Pas de Modification 3.0 France. 


\section{Małgorzata Małolepsza et Aneta Szymkiewicz, Hurra!!! Po Polsku 1}

Dagmara Gut

\section{RÉFÉRENCE}

Małgorzata Małolepsza et Aneta Szymkiewicz, Hurra!!! Po Polsku 1, Cracovie, Prolog, $2007,160 \mathrm{p}$. 
Ce livre fait partie d'une série destinée à l'apprentissage $\mathrm{du}$ polonais langue étrangère conforme aux normes du Cadre européen commun de référence (CECR) pour les langues. Le manuel, les cahiers d'exercices et les CD audio qui l'accompagnent ont été créés dans le cadre du programme Socrates-LINGUA 2. Ce programme a pour but de développer l'enseignement des langues étrangères en Europe ainsi que de promouvoir les langues et les cultures des pays membres de l'Union Européenne.

2 Le manuel d'étude se divise en vingt chapitres, correspondant à 120 heures de cours. Il vise au développement des quatre compétences en communication : expression orale, compréhension orale, production écrite et compréhension écrite. L'apprenant avance, guidé par le lecteur, grâce aux multiples exercices qui incitent à parler, lire, écrire et comprendre les native speakers polonais. Les textes, authentiques pour la plupart, concernent des sujets d'actualité et décrivent la vie en Pologne : la culture, les traditions, l'histoire... Les mots croisés, les jeux, les quizz et les exercices mnémotechniques systématisent et facilitent la concentration et l'assimilation du cours.

3 Le cahier d'exercices permet à l'étudiant de revoir les problèmes grammaticaux ainsi que le nouveau vocabulaire de manière cohérente et intéressante.

4 L'enseignant dispose d'un guide, de tests de niveau lui permettant d'évaluer les progrès de l'étudiant ainsi que d'une grammaire trilingue (polonais, allemand et anglais), accompagnant les manuels » Hurra!!! Po polsku 1 » (niveau A1), « Hurra!!! Po polsku 2 » (niveau A2) et « Hurra!!! Po polsku $3 »$ (niveau B1).

5 Créée dans un esprit de communication, cette série propose une méthode d'enseignement cohérente et moderne qui valorise l'apprentissage autonome. La collection « Hurra!!! Po polsku » est une bonne préparation à l'obtention du certificat de niveau B1.

\section{INDEX}

Mots-clés : didactique des langues étrangères, langue polonaise 


\section{AUTEURS}

\section{DAGMARA GUT}

A.T.E.R. dans la section de polonais à l'Université Charles-de-Gaulle Lille3. Doctorante en Lettres Slaves. Sujet de thèse : Quels usages des TICE en présentiel enrichi permettent d'optimiser l'apprentissage d'une L2 dans une approche par compétences. Le cas de la compréhension de l'oral en polonais langue étrangère. 